This is the peer reviewed version of the following article: Orri, M., Geoffroy, M. C., Turecki, G., Feng, B., Brendgen, M., Vitaro, F., Dionne, G., Paquin, S., Galera, C., Renaud, J., Tremblay, R. E., Côté, S. M., \& Boivin, M. (2020). Contribution of genes and environment to the longitudinal association between childhood impulsive-aggression and suicidality in adolescence. Journal of child psychology and psychiatry, and allied disciplines,61(6), 711-720., which has been published in final form at https://doi.org/10.1111/jcpp.13163. This article may be used for non-commercial purposes in accordance with Wiley Terms and Conditions for Use of Self-Archived Versions. 


\section{Contribution of genes and environment to the longitudinal association between childhood impulsive-aggression and suicidality in adolescence}

Running head: Childhood impulsive-aggression and adolescent suicidality

Massimiliano Orri, PhD; ${ }^{1,2}$ Marie-Claude Geoffroy, PhD1, ${ }^{1,3 *}$; Gustavo Turecki, MD, PhD $;{ }^{1}$ Bei Feng, MS; ${ }^{4}$ Mara Brendgen, $\mathrm{PhD} ;{ }^{5}$ Frank Vitaro, $\mathrm{PhD} ;{ }^{6}$ Ginette Dionne, $\mathrm{PhD} ;{ }^{6}$ Stephane Paquin, $\mathrm{PhD} ;{ }^{4,7}$ Cedric Galera, MD, $\mathrm{PhD} ;{ }^{2}$ Johanne Renaud, MD, MSc; Richard E. Tremblay, PhD; ${ }^{910}$ Sylvana M. Côté, PhD; ${ }^{11}$ Michel Boivin, $\mathrm{PhD}^{4 *}$

${ }^{1}$ McGill Group for Suicide Studies, Douglas Mental Health University Institute, Department of Psychiatry, McGill University, Montréal, Québec, Canada

${ }^{2}$ Bordeaux Population Health Research Centre, INSERM U1219, University of Bordeaux, Bordeaux, France

${ }^{3}$ Department of Educational and Counselling Psychology, McGill University, Montréal, Québec, Canada

${ }^{4}$ School of Psychology, Université Laval, Québec city, Québec, Canada

${ }^{5}$ Department of Psychology, Université du Québec à Montréal, Montréal, Québec, Canada

${ }^{6}$ School of Psychoéducation, University of Montréal, Montréal, Canada

${ }^{7}$ Department of Sociology, University of Montréal, Montréal, Québec, Canada

${ }^{8}$ Manulife Centre for Breakthroughs in Teen Depression and Suicide Prevention, Montréal, Québec, Canada

${ }^{9}$ Department of Pediatrics and Psychology, University of Montréal, Montréal, Québec, Canada

${ }^{10}$ School of Public Health, University College Dublin, Dublin, Ireland

${ }^{11}$ Department of Social and Preventive Medicine, University of Montréal, Montréal, Québec, Canada

* Shared senior authorship

\section{Corresponding:}

Prof. Michel Boivin, École de psychologie, Université Laval, 2325 Allée des Bibliothèques, Québec city, Québec, Canada, G1V 0A6 (michel.boivin@psy.ulaval.ca)

Prof. Marie-Claude Geoffroy, Department of School/Applied Child Psychology, McGill University, 3700 McTavish Street, Montreal, Québec, Canada, H3A 1Y2 (marie-claude.geoffroy@mcgill.ca)

Word count: 6263 


\begin{abstract}
Background. Population-based and family studies showed that impulsive-aggression predicts suicidality, however the underlying etiological nature of this association is poorly understood. The objective was to determine the contribution of genes and environment to the association between childhood impulsiveaggression and serious suicidal ideation/attempt in young adulthood.
\end{abstract}

Methods. N=862 twins (435 families) from the Quebec Newborn Twin Study were followed up from birth to 20 years. Repeated measures of teacher-assessed impulsive-aggression were modeled using a geneticallyinformed latent growth model including intercept and slope parameters reflecting individual differences in the baseline level (age 6 years) and in the change (increase/decrease) of impulsive-aggression during childhood (6-to-12 years), respectively. Lifetime suicidality (serious suicidal ideation/attempt) was selfreported at 20 years. Associations of impulsive-aggression intercept and slope with suicidality was decomposed into additive genetic (A) and unique environmental (E) components.

Results. Additive genetic factors accounted for an important part of individual differences in impulsiveaggression intercept $(A=90 \%, E=10 \%)$, and slope $(A=65 \%, E=35 \%)$. Genetic $(50 \%)$ and unique environmental (50\%) factors equally contributed to suicidality. We found that $38 \%$ of the genetic factors accounting for suicidality were shared with those underlying impulsive-aggression slope, whereas $40 \%$ of the environmental factors accounting for suicidality were shared with those associated with impulsiveaggression intercept. The genetic correlation between impulsive-aggression slope and suicidality was 0.60 , $\mathrm{p}=0.027$.

Conclusions. Genetic and unique environmental factors underlying suicidality significantly overlap with those underlying childhood impulsive-aggression. Future studies should identify putative genetic and environmental factors to inform prevention.

Keywords. Suicide attempt, suicidal ideation, impulsive-aggression, twin study, behavioral genetics, longitudinal 


\section{Introduction}

Suicide is a leading cause of death worldwide across all ages, and second-to-third cause of mortality in youths under age 25 years (Hawton, Saunders, \& O’Connor, 2012; Turecki \& Brent, 2016; WHO, 2015). Adolescent suicidal ideation and suicide attempt (i.e., suicidality) are the main risk factors for suicide (Nock et al., 2008), and are thus considered key targets for suicide prevention.

Beside the established role of mental health problems, such as depression and schizophrenia (Arsenault-Lapierre, Kim, \& Turecki, 2004), impulsive-aggressive behavioral traits have shown to contribute to suicidality (Brent et al., 2015; McGirr et al., 2008; McGirr et al., 2009; McGirr \& Turecki, 2007; Turecki, Ernst, Jollant, Labonté, \& Mechawar, 2012). Accordingly, impulsive-aggression is considered the most important behavioral endophenotype for suicidal behaviors (Mann et al., 2009; Turecki et al., 2012), especially in youth (McGirr et al., 2008). However, little is known about the process underlying the association between impulsive-aggression and suicidality. Both genetic and environmental factors may underlie this association. For example, family studies showed that the heritability of suicidal behaviors (estimated at 30-50\%; Fu et al., 2002; Mann et al., 2009; Pedersen \& Fiske, 2010) is substantially explained by impulsive-aggression (Brent et al., 2015; McGirr et al., 2009), suggesting that the two phenotypes share a common genetic etiology. However, environmental processes may also play an important role. For example, impulsive-aggression was found associated with putative environmental risk factors for suicidality (Franklin et al., 2016; Geoffroy et al., 2016; Nock et al., 2013; Orri et al., 2019), such as bullying/victimization (Michel Boivin, Brendgen, Vitaro, et al., 2013; Camodeca, Goossens, Terwogt, \& Schuengel, 2002), hostile-reactive parenting (Barker \& Salekin, 2012; Burton, Florell, \& Gore, 2013; Camodeca et al., 2002; Vitaro, Barker, Boivin, Brendgen, \& Tremblay, 2006), and socioeconomic adversity (Fergusson, Boden, \& Horwood, 2013), thus suggesting common environmental risks. Documenting the contribution of genes and environment to the association between impulsive-aggression and suicidality is crucial for understanding their unique and shared etiology, and thus to improve suicide prevention. To our knowledge, no study to date has examined this important question.

Impulsive-aggressive behaviors follow a typical developmental trajectory during the life course. In the general population, the highest frequency of impulsive-aggressive behaviors is exhibited during early 
childhood, and is followed by a progressive decline in middle childhood and adolescence (Barker, Tremblay, Nagin, Vitaro, \& Lacourse, 2006; Teymoori et al., 2018; Tremblay, Vitaro, \& Côté, 2018). However, there are large individual differences in this general developmental course. Indeed, while most children show decreasing levels of impulsive-aggression (or related constructs, such as irritability), those showing persistently high or increasing levels are more at risk of subsequent mental health problems in adolescence, including suicidality (Brezo et al., 2008; Orri et al., 2019; Orri, Perret, Turecki, \& Geoffroy, 2018). These findings suggest that individual variability in baseline level and developmental change (i.e., decreasing vs stability/increasing) of impulsive-aggression may play a different role in subsequent suicidality. In line with this, genetically informed studies suggest that baseline level and developmental course of aggressive behaviors in childhood may have distinct genetic etiology (Lacourse et al., 2014; Paquin et al., 2017; Pingault, Viding, et al., 2015).

In the present study, we used a population-based longitudinal twin cohort to document the genetic and environmental contributions to the association between childhood impulsive-aggression (from age 6 to 12 years) and later suicidality in adolescence/young adulthood (by age 20 years; hereafter referred to as adolescence). Specifically, using the twin method, we partitioned the covariation between impulsiveaggression and suicidality into genetic and environmental components. Additionally, taking advantage of longitudinal data, we documented the extent to which genetic and environmental factors contributed to (1) the association between baseline levels of impulsive-aggression and later suicidality, and (2) the association between change in impulsive-aggression across middle childhood (from age 6 to 12 years) and later suicidality.

\section{Methods}

\section{Participants}

We used data from the Quebec Newborn Twin Study (QNTS), a population-based cohort initially including 1324 twins (i.e., 662 pairs) born between April 1 ${ }^{\text {st }}, 1995$ and December 31 $1^{\text {st }}, 1998$ in the greater Montreal area of the province of Québec, Canada (Boivin et al., 2013). Families were initially enrolled in the QNTS if the mother was fluent in French or English, and the twins had no major medical complications at birth. 
Zygosity was initially assessed via questionnaire and confirmed with DNA tests on a subsample of $n=123$ same-sex pairs (96\% correspondence; Forget-Dubois et al., 2003) Participant twins of QNTS did not differ from same-age singleton children from a representative cohort from Québec (Paquin et al., 2017). In this study, we considered teacher ratings of the twins' impulsive-aggression from age 6 to 12 years, and subsequent self-reported lifetime suicidality by age 20 years. The sample for the final model was 862 participants (335 monozygotic and 527 dizygotic twins; Table 1) still enrolled in the cohort at age 20 (i.e., thus having data on suicide variables). Missing data in the other variables, including impulsive-aggression (missing data range, 30\% to 40\%) was handled using Full Information Maximum Likelihood approach.

\section{Ethical considerations}

The QNTS protocol was approved by Ste-Justine Hospital Research Ethics Board, and written informed consent was obtained from all participants.

\section{Assessment of impulsive-aggression and suicidality}

When twins were $6,7,9,10$, and 12 years of age, school teachers rated twins' impulsive-aggressive behaviors in the past 6 months, using 4 items from Dodge \& Coie (1987): overreacts angrily to accidents; blames others in fight; when teased, strikes back; reacts in an aggressive manner when contradicted. These behaviors were rated on a 3 -point Likert scale $(0=$ never $/ 1=$ sometimes $/ 2=$ often $)$, and then averaged at each age (range 0-2, higher scores indicating higher impulsive-aggression; $\alpha=0.87-0.89$; Poulin $\&$ Boivin, 2000). Children's behavior was assessed by a different teacher each year, thus reducing risks of rater bias.

Lifetime suicidality was assessed through self-reports at age 20 years. Adolescents were asked three questions regarding suicidal thoughts (“have you ever thought about suicide?”; yes/no), serious suicidal ideation ("If you thought about suicide, did you have a plan to do that"; yes/no), and (if yes) suicide attempt (“Did you ever attempt suicide?”; yes/no). As in previous studies (Côté et al., 2017; Geoffroy et al., 2016, 2018; Orri et al., 2019; Orri, Galera, et al., 2018), suicidality was operationalized as reporting serious suicidal ideation and/or suicide attempt (i.e., participants reporting uniquely suicidal thought were coded as no).

\section{Analysis}



measures of impulsive-aggression from age 6 to 12 years were modeled using latent growth curve. First, we estimated the best-fitting model of a phenotypic growth curve model (i.e., not considering genetic and environmental similarities among twins), which included intercept and slope parameters. The intercept parameter modeled the individual differences in the baseline level of impulsive-aggression, whereas the slope parameter modeled the individual differences in the linear rate of change of impulsive-aggression during childhood (i.e., 6-12 years). Second, using a Cholesky decomposition, we modeled the contribution of genetic and environmental factors to the intercept and slope parameters. In this model, the variance of intercept and slope, as well as their covariance are decomposed into an additive genetic component (A), i.e., genetic factors that combine additively (assumed to be 100\% shared for monozygotic twins, and 50\% for dizygotic twins), a common or shared environmental component (C), i.e., environmental factors that are shared by the twins and contribute to their similarity (assumed to be $100 \%$ shared for both monozygotic and dizygotic twins), and a unique or nonshared environmental component (E), i.e., environmental factors that contribute to differences among twins of the same family, including measurement error (assumed to be unshared for both monozygotic and dizygotic twins; ACE model). The covariance between intercept and slope reflects the proportion of genetic and environmental variance shared by the baseline level (i.e., intercept) and developmental change (i.e., slope) of impulsive-aggression. Third, using the likelihood ratio test and the Akaike Information Criterion, the estimated ACE model was compared with an AE model (in which the common environmental component was constrained to zero), a CE model (in which the additive genetic component was constrained to zero) and an E model (in which both the additive genetic component and the common environmental component were constrained to zero) to identify the most parsimonious model.

Genetic and environmental contributions to suicidality. The contribution of genetic and environmental factors to suicidality was estimated by fitting a univariate ACE model to the suicidality measure. Nested ACE, AE, CE, and E models were compared as previously described.

Genetic and environmental contributions to the association between impulsive-aggression and suicidality. In the final step, impulsive-aggression intercept, impulsive-aggression slope, and suicidality were considered in 
the same multivariate Cholesky model. We calculated the genetic and environmental contribution to the association between childhood impulsive-aggression and later suicidality, that is the proportion of suicidality variance accounted for by the genetic and environmental factors underlying impulsive-aggression intercept and slope. Additionally, we computed the proportion of genetic factors in suicidality accounted for by genetic factors underlying impulsive-aggression intercept and slope, allowing us to calculate the genetic correlation $\left(r_{g}\right)$ between the 2 phenotypes.

The model was adjusted for sex and age using residualized scores, and 95\% confidence intervals of all estimates (including the phenotypic model) were determined using bootstrap (10000 replications). All models were estimated using Mplus version 7.4 (Muthén \& Muthén, 1998) accounting for the binary nature of the suicidality outcome using the WLSMV (weighted least square mean and variance adjusted) estimator (liability threshold model). This estimator is also less sensitive of violations of normality in the distribution of the continuous variables, such as impulsive-aggression.

\section{Results}

\section{Prevalence of suicidality and phenotypic associations}

In our sample, 79 of 862 participants $(9.1 \%)$ reported serious suicidal ideation and/or attempt by age 20 years (Table 2). Suicidality was more frequent among dizygotic than monozygotic twins. The strength of the association between impulsive-aggression and suicidality ranged from OR $1.27(0.73-2.18)$ to OR 2.33 (1.29-4.19) (Table 3). At 12 years, the OR for this association was 3.31 (1.27-8.64) for monozygotic twins and $1.98(0.92-4.23)$ for dizygotic twins. As shown in Figure 1, impulsive-aggression score tended to decrease from early childhood to adolescence, especially when children reached age 12 . Cross-time (stability) correlations for impulsive-aggression ranged 0.39 to 0.60 for consecutive time points.

\section{Genetic and environmental contributions to impulsive-aggression and suicidality}

For both impulsive-aggression at each time point $(6,7,9,10$ and 12 years) and suicidality, the AE model was selected as the most parsimonious (supplemental Tables 1 and 2). In the final growth model, additive genetic factors accounted for most of the individual differences in impulsive-aggression intercept (90\%), while additive genetic and environmental factors respectively accounted for $65 \%$ and $35 \%$ of the individual 
differences in impulsive-aggression slope (Figure 1 and Table 4). Individual differences in suicidality were accounted for by both genetic (50\%) and unique environmental (50\%) factors (Table 3 and Figure 1).

\section{Genetic and environmental contributions to the association between impulsive-aggression and suicidality}

We found that $40 \%$ (20\% of $50 \%$ ) of the genetic factors underlying suicidality were accounted for by genetic factors underlying impulsive-aggression. However, most of these genetic factors stem from the slope ( $19 \%$ of $50 \%$, i.e., $38 \%)$ rather than the intercept ( $1 \%$ of $50 \%$, i.e., $2 \%)$. The corresponding genetic correlations for slope and intercept were, respectively, 0.60 (standard error, SE, $0.27 ; \mathrm{p}=0.027$ ) and 0.08 (SE, $0.24, \mathrm{p}=0.735)$. The remaining suicidality genetic variance $(60 \%$, i.e., $30 \%$ of $50 \%)$ was not shared with impulsive-aggression. We also found that $42 \%(23 \%$ of $50 \%)$ of the environmental factors underlying suicidality was shared with those underlying impulsive-aggression. However, in contrast to genetic factors, these environmental factors stem mainly from the intercept (22\% of 50\%; i.e., $40 \%$ ) rather than from the slope $(1 \%$ of $50 \%$; i.e., $2 \%)$. The remaining $28 \%$ of the environmental variance of suicidality was not shared with impulsive-aggression.

\section{Discussion}

Previous studies showed that impulsive-aggression is associated with suicidality, but the underlying etiological nature of this association had not yet been clarified. Using a longitudinal twin design, this study documented the role of genetic and environmental factors in this association. Our findings indicated that genetic and unique (nonshared) environmental factors, but not shared environmental factors, contributed to both impulsive-aggression and suicidality as well as to their association. Individual differences in adolescent suicidality risk were shared with genetic factors underlying changes in impulsive-aggression across childhood. Environmental factors underlying childhood impulsive-aggression also contributed to individual differences in suicidality. However, these factors were shared with environmental factors underlying baseline level, rather than changes in impulsive-aggression across childhood. These findings have important implications for understanding the association between impulsive-aggression and suicidality, as well as for future research. 
First, at the phenotypic level, the association between impulsive-aggression and suicidality increased at 12 years, perhaps due to the emerging role of puberty. The possibility of an increasing role of impulsiveaggression regarding suicidality requires deeper exploration, but is in line with previous studies (Patton et al., 2007) underlining the important biological and psychosocial changes associated with puberty (Patton \& Viner, 2007). The role of puberty deserves further exploration, particularly because we did not have information about suicidality onset in our sample. Indeed, the role of puberty in the association between impulsive-aggression and suicidality may differ depending on whether suicidality onset was in early adolescence (e.g., age 13) versus late adolescence (e.g., age 20). It is also worth noting that irritability and impulsive-aggression have been found to be associated with depressive symptoms in previous studies (e.g., Stringaris, Maughan, Copeland, Costello, \& Angold, 2013; Brent et al., 2015), suggesting that impulsiveaggression could predict suicidal ideation, and not attempt. However, other studies found that irritability (Orri et al., 2019) and impulsive-aggression (Hartley, Pettit, \& Castellanos, 2018) were associated with both ideation and attempts. Furthermore, other authors pointed out to impulsive traits as explanatory factors in the transition from ideation to attempt (O’Connor \& Kirtley, 2018). As our sample size did not allow us to disentangle more in-depth the association of impulsive-aggression with suicidal ideation versus suicide attempt, larger studies of this kind are required.

Second, consistent with previous studies (Fu et al., 2002; Mann et al., 2009; Pedersen \& Fiske, 2010), we found genetic and unique environmental contributions to suicidality, but no contribution of shared environmental factors. Similarly, consistent with previous reports, we found a substantial contribution of genetic factors to impulsive-aggression (Tuvblad \& Baker, 2011; Waltes, Chiocchetti, \& Freitag, 2016). The findings of genetic and environmental underpinnings of changes in impulsive-aggression over childhood, which were distinct from those underlying the baseline level of symptoms, mirror similar findings for hyperactivity (Pingault, Viding, et al., 2015) and conduct disorders (Pingault, Rijsdijk, Zheng, Plomin, \& Viding, 2015).

Third, the finding of a significant genetic overlap between impulsive-aggression and suicidality are in line with previous psychological autopsy studies (McGirr et al., 2009) and longitudinal familial studies (Brent et al., 2015), and suggests that suicidal behaviors and impulsive-aggression share genetic 
vulnerabilities and perhaps underlying biological mechanisms (Mann et al., 2009). However, the present findings add further to this association by showing that genetic factors for suicidality overlap with genetic factors underlying the change in impulsive-aggression over time - not the initial level of symptoms in early childhood. Future molecular studies should aim to identify the genes accounting for this shared heritability. Genes involved in the regulation of the serotoninergic (eg, 5-hydroxyindoleacetic acid, monoamine oxidase) and dopaminergic (eg, tyrosine hydroxylase, dopamine receptor DRD2) systems, as well as in the hypothalamic-pituitary-adrenal axis (eg, corticotrophin-release hormone gene) have been found to be associated with both suicidality and impulsive-aggression (Brezo et al., 2010; Mann, 2001; Waltes et al., 2016; Zai et al., 2012). However, these studies rarely investigated impulsive-aggression and suicidality together in the same sample. Therefore, a promising avenue for future studies may be to focus on genes that are likely to account for the covariation of those traits in a same sample. Additionally, it would be important for such studies to adopt a longitudinal approach to identify genetic factors specifically accounting for the developmental course of impulsive-aggression.

Fourth, we found that the association between impulsive-aggression and suicidality was also significantly accounted for by environmental factors. That is, beyond genetic factors, exposure to unique life experiences accounted for a substantial part of the phenotypic association between impulsive-aggression and suicidality. In contrast to the pattern observed for genetic factors, we found that suicidality shared such environmental factors with the baseline level of impulsive-aggression, pointing to putative environmental factors that could be involved early in childhood and persist over time. For example, previous studies showed that impulsive-aggression lead to increased interpersonal problems, such as peer rejection and victimization (Boivin \& Hymel, 1997; Boivin, Petitclerc, Feng, \& Barker, 2010; Camodeca et al., 2002; Card \& Little, 2006; Salmivalli \& Nieminen, 2002), which starts early in childhood, is chronic (Barker et al., 2008; Geoffroy et al., 2018), and a documented risk factor for suicidal thoughts and behaviors (Geoffroy et al., 2016; Geoffroy, Gunnell, \& Power, 2014). Future studies should aim to identify and test the role of putative environmental factors in the association between impulsive-aggression and suicidality, as they might be promising targets for early preventive interventions. For example, the Good Behavior Game, an intervention designed to reduce aggression, was found to reduce suicidal behaviors via environmental 
mechanisms such as improving social adaptation into the classroom (Newcomer et al., 2016). Understanding the role of such early interventions in reducing environmental risks for impulsive-aggressive and suicidality may open important clinical avenues. It is also important to note that in twin designs, unique environmental factors also include measurement errors. Therefore, future studies also need to better quantify the strength of the association and the causal nature of specific environmental influences.

Fifth, beyond the genetic and environmental factors contributing to suicidality that were shared with impulsive-aggression, an important proportion was unique to suicidality. Future studies should further investigate these factors, including the possible shared etiology with mood disorders. Results from prior studies are inconsistent. For example, evidence from family (Egeland \& Sussex, 1985) and molecular (Brezo et al., 2010) studies showed that family transmission of suicidality is partly independent from family transmission of mood disorders, suggesting that impulsive-aggression and mood disorders explain different parts of suicidality genetic variance. Another study showed genetic and shared environmental factors common to suicidal ideation, depression, and conduct disorder (Linker, Gillespie, Maes, Eaves, \& Silberg, 2012). To the extent that conduct disorders and impulsive-aggression overlaps, these finding suggests that the genetic contributions to impulsive-aggression and depression partially overlap. Finally, another study indicated that suicidality risk in children presenting with irritability (a construct closely related to impulsiveaggression) was significantly higher when those children showed concomitant high levels of depressive/anxious mood (Orri, Galera, et al., 2018). This may suggest gene×gene interactions whereby the genetic association between impulsive-aggression and suicidality vary according to the level of depressive/anxious symptomatology. Those mechanisms should be tested in well-designed geneticallyinformed studies.

\section{Strengths and limitations}

This study was conducted using a large population-based sample of twins followed-up yearly or biyearly for 14 years, which allowed us to explore developmental aspects of the association between impulsiveaggression and suicidality. Impulsive-aggression and suicidality were respectively assessed using teacherreports and self-reports, thus ensuring that our estimates were not inflated by shared method variance bias. However, the findings must be interpreted in light of the following limitations. First, our sample was not 
representative of the general population. However, the sample was originally drawn from a birth registry and sociodemographic characteristics did not differ from a representative sample of same-age singleton children from the same region (Paquin et al., 2017). It is unlikely that lack of representativeness would bias our estimates of the genetic and environmental influences. Second, given the size of our sample and the low prevalence of our outcome, we were unable to test for qualitative or quantitative sex differences. Similarly, our sample size did not enable us to investigate suicide attempt and suicidal ideation separately. However, suicidality can be conceptualized as a continuum from passive suicidal though to lethal suicide attempts, and our measure of suicidality captured active suicidal ideation (i.e., plan) rather than passive suicidal ideation. Third, although serious suicidal ideation and suicide attempt are very infrequent before age 12 , we cannot exclude this possibility due to our lifetime measure of suicidality. However, even in that case, the overlap between impulsive-aggression and suicidality would be minimal and unlikely to substantially bias our findings. Fourth, although AE models were the best fitting models in our sample, removing the C component may result in inflated estimate of the genetic (A) component and of genetic correlations. Finally, our study suffers from the inherent limitations of the twin design, such as the assumption of limited gene $\times$ environment interaction or assortative mating.

\section{Conclusion}

This population-based twin study shows that a significant proportion of the genetic and unique environmental factors underlying adolescent suicidality are overlapping with genetic and environmental factors underlying childhood impulsive-aggression. Our findings suggest different developmental processes for the genetic and environmental influences on suicidality. Indeed, genetic factors for suicidality overlap with genetic factors influencing how impulsive-aggression changes during childhood, while environmental factors for suicidality overlap with environmental factors influencing impulsive-aggression baseline level. Future studies should identify the specific factors and mechanisms (both genetic and environmental) that contribute to these shared influences in order to further clarify the etiology of suicidality and to inform preventive interventions. 
Acknowledgements. We gratefully acknowledge the on-going contribution of families, children and teachers in the Quebec Newborn Twin Study (QNTS). We also thank Hélène Paradis for data preparation. Dr Orri reports receiving a postdoctoral research fellowship from Canadian Institutes of Health Research (CIHR) and a grant from the European Union's Horizon 2020 research and innovation program (\#793396). Dr Geoffroy reports receiving funding from the American Foundation for Suicide Prevention. Dr Boivin reports holding a Canada Research Chair (Tier 1) in Child Development. Dr Turecki reports holding a Canada Research Chair (Tier 1) and a NARSAD Distinguished Investigator Award, and being supported by grants from the Canadian Institute of Health Research (CIHR) (FDN148374 and EGM141899). Drs Boivin, Geoffroy and Turecki reports being supported by the Fonds de recherche du Québec - Santé (FRQS) through the Quebec Network on Suicide, Mood Disorders and Related Disorders. Drs Côté and Geoffroy report being research fellows of the Fonds de Recherche du Québec. No other disclosures were reported. Funding for the primary school data collections comes from Social Science and Humanities Research Council (SSHRC) grant 410-2001-1475. Funding for the age 20 data collection comes from SSHRC grant 435-20141536. Funders have no role in study design, data analysis, and interpretation of the data, writing of the manuscript. 


\section{References}

Arsenault-Lapierre, G., Kim, C., \& Turecki, G. (2004). Psychiatric diagnoses in 3275 suicides : A metaanalysis. BMC Psychiatry, 4, 37. https://doi.org/10.1186/1471-244X-4-37

Barker, E. D., Boivin, M., Brendgen, M., Fontaine, N., Arseneault, L., Vitaro, F., ... Tremblay, R. E. (2008). Predictive validity and early predictors of peer-victimization trajectories in preschool. Archives of General Psychiatry, 65(10), 1185-1192. https://doi.org/10.1001/archpsyc.65.10.1185

Barker, E. D., \& Salekin, R. T. (2012). Irritable oppositional defiance and callous unemotional traits : Is the association partially explained by peer victimization? Journal of Child Psychology and Psychiatry, and Allied Disciplines, 53(11), 1167-1175. https://doi.org/10.1111/j.1469-7610.2012.02579.x

Barker, E. D., Tremblay, R. E., Nagin, D. S., Vitaro, F., \& Lacourse, E. (2006). Development of male proactive and reactive physical aggression during adolescence. Journal of Child Psychology and Psychiatry, and Allied Disciplines, 47(8), 783-790. https://doi.org/10.1111/j.1469-7610.2005.01585.x

Boivin, M., \& Hymel, S. (1997). Peer experiences and social self-perceptions: A sequential model. Developmental Psychology, 33(1), 135-145.

Boivin, Michel, Brendgen, M., Dionne, G., Dubois, L., Pérusse, D., Robaey, P., ... Vitaro, F. (2013). The Quebec Newborn Twin Study Into Adolescence : 15 Years Later. Twin Research and Human Genetics, 16(1), 64-69. https://doi.org/10.1017/thg.2012.129

Boivin, Michel, Brendgen, M., Vitaro, F., Forget-Dubois, N., Feng, B., Tremblay, R. E., \& Dionne, G. (2013). Evidence of gene-environment correlation for peer difficulties : Disruptive behaviors predict early peer relation difficulties in school through genetic effects. Development and Psychopathology, 25(1), 79-92. https://doi.org/10.1017/S0954579412000910

Boivin, Michel, Petitclerc, A., Feng, B., \& Barker, E. D. (2010). The developmental trajectories of peer victimization in middle to late childhood and the changing nature of their behavioral correlates. Merrill-Palmer Quarterly, 56(3), 231-260. https://doi.org/10.1353/mpq.0.0050

Brent, D. A., Melhem, N. M., Oquendo, M., Burke, A., Birmaher, B., Stanley, B., ... Mann, J. J. (2015). Familial Pathways to Early-Onset Suicide Attempt : A 5.6-Year Prospective Study. JAMA Psychiatry, 72(2), 160-168. https://doi.org/10.1001/jamapsychiatry.2014.2141 
Brezo, J., Bureau, A., Mérette, C., Jomphe, V., Barker, E. D., Vitaro, F., ... Turecki, G. (2010). Differences and similarities in the serotonergic diathesis for suicide attempts and mood disorders : A 22-year longitudinal gene-environment study. Molecular Psychiatry, 15(8), 831-843. https://doi.org/10.1038/mp.2009.19

Brezo, Jelena, Barker, E. D., Paris, J., Hébert, M., Vitaro, F., Tremblay, R. E., \& Turecki, G. (2008). Childhood trajectories of anxiousness and disruptiveness as predictors of suicide attempts. Archives of Pediatrics \& Adolescent Medicine, 162(11), 1015-1021. https://doi.org/10.1001/archpedi.162.11.1015

Burton, K. A., Florell, D., \& Gore, J. S. (2013). Differences in Proactive and Reactive Aggression in Traditional Bullies and Cyberbullies. Journal of Aggression, Maltreatment \& Trauma, 22(3), 316-328. https://doi.org/10.1080/10926771.2013.743938

Camodeca, M., Goossens, F. A., Terwogt, M. M., \& Schuengel, C. (2002). Bullying and victimization among school-age children: Stability and links to proactive and reactive aggression. Social Development, 11(3), 332-345. https://doi.org/10.1111/1467-9507.00203

Card, N. A., \& Little, T. D. (2006). Proactive and reactive aggression in childhood and adolescence: A meta-analysis of differential relations with psychosocial adjustment. International Journal of Behavioral Development, 30(5), 466-480. https://doi.org/10.1177/0165025406071904

Côté, S. M., Orri, M., Brendgen, M., Vitaro, F., Boivin, M., Japel, C., ... Tremblay, R. E. (2017). Psychometric properties of the Mental Health and Social Inadaptation Assessment for Adolescents (MIA) in a population-based sample. International Journal of Methods in Psychiatric Research, n/a-n/a. https://doi.org/10.1002/mpr.1566

Dodge, K. A., \& Coie, J. D. (1987). Social-information-processing factors in reactive and proactive aggression in children's peer groups. Journal of Personality and Social Psychology, 53(6), 1146-1158.

Egeland, J. A., \& Sussex, J. N. (1985). Suicide and family loading for affective disorders. JAMA, 254(7), 915-918.

Fergusson, D. M., Boden, J. M., \& Horwood, L. J. (2013). Childhood self-control and adult outcomes : Results from a 30-year longitudinal study. Journal of the American Academy of Child and Adolescent Psychiatry, 52(7), 709-717.e1. https://doi.org/10.1016/j.jaac.2013.04.008 
Forget-Dubois, N., Pérusse, D., Turecki, G., Girard, A., Billette, J.-M., Rouleau, G., ... Tremblay, R. E. (2003). Diagnosing Zygosity in Infant Twins: Physical Similarity, Genotyping, and Chorionicity. Twin Research and Human Genetics, 6(6), 479-485. https://doi.org/10.1375/twin.6.6.479

Franklin, J. C., Ribeiro, J. D., Fox, K. R., Bentley, K. H., Kleiman, E. M., Huang, X., ... Nock, M. K. (2016). Risk Factors for Suicidal Thoughts and Behaviors: A Meta-Analysis of 50 Years of Research. Psychological Bulletin. https://doi.org/10.1037/bul0000084

Fu, Q., Heath, A. C., Bucholz, K. K., Nelson, E. C., Glowinski, A. L., Goldberg, J., .. Eisen, S. A. (2002). A twin study of genetic and environmental influences on suicidality in men. Psychological Medicine, $32(1), 11-24$.

Geoffroy, Marie-Claude, Boivin, M., Arseneault, L., Renaud, J., Perret, L. C., Turecki, G., ... Côté, S. M. (2018). Childhood trajectories of peer victimization and prediction of mental health outcomes in midadolescence: A longitudinal population-based study. CMAJ, 190(2), E37-E43. https://doi.org/10.1503/cmaj.170219

Geoffroy, Marie-Claude, Boivin, M., Arseneault, L., Turecki, G., Vitaro, F., Brengden, M., ... Côté, S. M. (in press). Association between peer victimization and suicidal ideation and suicide attempt during adolescence: Results from a prospective population-based birth cohort. Journal of the American Academy of Child and Adolescent Psychiatry.

Geoffroy, M.-C., Gunnell, D., \& Power, C. (2014). Prenatal and childhood antecedents of suicide : 50-year follow-up of the 1958 British Birth Cohort study. Psychological Medicine, 44(6), 1245-1256. https://doi.org/10.1017/S003329171300189X

Hartley, C. M., Pettit, J. W., \& Castellanos, D. (2018). Reactive Aggression and Suicide-Related Behaviors in Children and Adolescents : A Review and Preliminary Meta-Analysis. Suicide and Life-Threatening Behavior, 48(1), 38-51. https://doi.org/10.1111/sltb.12325

Hawton, K., Saunders, K. E. A., \& O’Connor, R. C. (2012). Self-harm and suicide in adolescents. Lancet (London, England), 379(9834), 2373-2382. https://doi.org/10.1016/S0140-6736(12)60322-5 
Hu, L., \& Bentler, P. M. (1999). Cutoff criteria for fit indexes in covariance structure analysis : Conventional criteria versus new alternatives. Structural Equation Modeling: A Multidisciplinary Journal, 6(1), 155. https://doi.org/10.1080/10705519909540118

Lacourse, E., Boivin, M., Brendgen, M., Petitclerc, A., Girard, A., Vitaro, F., ... Tremblay, R. E. (2014). A longitudinal twin study of physical aggression during early childhood : Evidence for a developmentally dynamic genome. Psychological $\quad$ Medicine, 44(12), https://doi.org/10.1017/S0033291713003218

Linker, J., Gillespie, N. A., Maes, H., Eaves, L., \& Silberg, J. L. (2012). Suicidal ideation, depression, and conduct disorder in a sample of adolescent and young adult twins. Suicide \& Life-Threatening Behavior, 42(4), 426-436. https://doi.org/10.1111/j.1943-278X.2012.00101.x

Mann, J. (2001). The Neurobiology and Genetics of Suicide and Attempted Suicide: A Focus on the Serotonergic System. Neuropsychopharmacology, 24(5), 467-477. https://doi.org/10.1016/S0893$133 \mathrm{X}(00) 00228-1$

Mann, J. J., Arango, V. A., Avenevoli, S., Brent, D. A., Champagne, F. A., Clayton, P., ... Wenzel, A. (2009). Candidate endophenotypes for genetic studies of suicidal behavior. Biological Psychiatry, 65(7), 556-563. https://doi.org/10.1016/j.biopsych.2008.11.021

McGirr, A., Renaud, J., Bureau, A., Seguin, M., Lesage, A., \& Turecki, G. (2008). Impulsive-aggressive behaviours and completed suicide across the life cycle: A predisposition for younger age of suicide. Psychological Medicine, 38(3), 407-417. https://doi.org/10.1017/S0033291707001419

McGirr, Alexander, Alda, M., Séguin, M., Cabot, S., Lesage, A., \& Turecki, G. (2009). Familial Aggregation of Suicide Explained by Cluster B Traits : A Three-Group Family Study of Suicide Controlling for Major Depressive Disorder. American Journal of Psychiatry, 166(10), 1124-1134. https://doi.org/10.1176/appi.ajp.2009.08111744

McGirr, Alexander, \& Turecki, G. (2007). The relationship of impulsive aggressiveness to suicidality and other depression-linked behaviors. Current Psychiatry Reports, 9(6), 460-466.

Muthén, L., \& Muthén, B. (1998). Mplus User's Guide. Seventh Edition. Los Angeles, CA: Muthén \& Muthén. 
Newcomer, A. R., Roth, K. B., Kellam, S. G., Wang, W., Ialongo, N. S., Hart, S. R., .. Wilcox, H. C. (2016). Higher Childhood Peer Reports of Social Preference Mediates the Impact of the Good Behavior Game on Suicide Attempt. Prevention Science, 17(2), 145-156. https://doi.org/10.1007/s11121-015-0593-4

Nock, M. K., Borges, G., Bromet, E. J., Cha, C. B., Kessler, R. C., \& Lee, S. (2008). Suicide and suicidal behavior. Epidemiologic Reviews, 30, 133-154. https://doi.org/10.1093/epirev/mxn002

Nock, M. K., Green, J. G., Hwang, I., McLaughlin, K. A., Sampson, N. A., Zaslavsky, A. M., \& Kessler, R. C. (2013). Prevalence, correlates, and treatment of lifetime suicidal behavior among adolescents : Results from the National Comorbidity Survey Replication Adolescent Supplement. JAMA Psychiatry, 70(3), 300-310. https://doi.org/10.1001/2013.jamapsychiatry.55

O’Connor Rory C., \& Kirtley Olivia J. (2018). The integrated motivational-volitional model of suicidal behaviour. Philosophical Transactions of the Royal Society B: Biological Sciences, 373(1754), 20170268. https://doi.org/10.1098/rstb.2017.0268

Orri, M., Galera, C., Turecki, G., Boivin, M., Tremblay, R. E., Geoffroy, M.-C., \& Côté, S. M. (in press). Pathways of association between childhood irritability and adolescent suicidality. Journal of the American Academy of Child \& Adolescent Psychiatry.

Orri, M., Galera, C., Turecki, G., Forte, A., Renaud, J., Boivin, M., ... Geoffroy, M.-C. (2018). Association of Childhood Irritability and Depressive/Anxious Mood Profiles With Adolescent Suicidal Ideation and Attempts. JAMA Psychiatry. https://doi.org/10.1001/jamapsychiatry.2018.0174

Orri, M., Gunnell, D., Richard-Devantoy, S., Bolanis, D., Boruff, J., Turecki, G., \& Geoffroy, M.-C. (2019). In-utero and perinatal influences on suicide risk: A systematic review and meta-analysis. The Lancet Psychiatry, O(0). https://doi.org/10.1016/S2215-0366(19)30077-X

Orri, M., Perret, L. C., Turecki, G., \& Geoffroy, M.-C. (2018). Association between irritability and suiciderelated outcomes across the life-course. Systematic review of both community and clinical studies. Journal of Affective Disorders, 239, 220-233. https://doi.org/10.1016/j.jad.2018.07.010

Paquin, S., Lacourse, E., Brendgen, M., Vitaro, F., Dionne, G., Tremblay, R. E., \& Boivin, M. (2017). Heterogeneity in the development of proactive and reactive aggression in childhood : Common and 
specific genetic - environmental factors. PloS One, 12(12), e0188730. https://doi.org/10.1371/journal.pone.0188730

Patton, G. C., Hemphill, S. A., Beyers, J. M., Bond, L., Toumbourou, J. W., McMorris, B. J., \& Catalano, R. F. (2007). Pubertal stage and deliberate self-harm in adolescents. Journal of the American Academy of Child and Adolescent Psychiatry, 46(4), 508-514. https://doi.org/10.1097/chi.0b013e31803065c7

Patton, G. C., \& Viner, R. (2007). Pubertal transitions in health. Lancet (London, England), 369(9567), 1130-1139. https://doi.org/10.1016/S0140-6736(07)60366-3

Pedersen, N. L., \& Fiske, A. (2010). Genetic influences on suicide and nonfatal suicidal behavior : Twin study findings. European Psychiatry, 25(5), 264-267. https://doi.org/10.1016/j.eurpsy.2009.12.008

Pingault, J.-B., Rijsdijk, F., Zheng, Y., Plomin, R., \& Viding, E. (2015). Developmentally dynamic genome : Evidence of genetic influences on increases and decreases in conduct problems from early childhood to adolescence. Scientific Reports, 5, 10053. https://doi.org/10.1038/srep10053

Pingault, J.-B., Viding, E., Galéra, C., Greven, C. U., Zheng, Y., Plomin, R., \& Rijsdijk, F. (2015). Genetic and Environmental Influences on the Developmental Course of Attention-Deficit/Hyperactivity Disorder Symptoms From Childhood to Adolescence. JAMA Psychiatry, 72(7), 651-658. https://doi.org/10.1001/jamapsychiatry.2015.0469

Poulin, F., \& Boivin, M. (2000). Reactive and proactive aggression: Evidence of a two-factor model. Psychological Assessment, 12(2), 115-122.

Salmivalli, C., \& Nieminen, E. (2002). Proactive and reactive aggression among school bullies, victims, and bully-victims. Aggressive Behavior, 28(1), 30-44. https://doi.org/10.1002/ab.90004

Teymoori, A., Côté, S. M., Jones, B. L., Nagin, D. S., Boivin, M., Vitaro, F., ... Tremblay, R. E. (2018). Risk Factors Associated With Boys' and Girls' Developmental Trajectories of Physical Aggression From Early Childhood Through Early Adolescence. JAMA Network Open, 1(8), e186364-e186364. https://doi.org/10.1001/jamanetworkopen.2018.6364

Tremblay, R. E., Vitaro, F., \& Côté, S. M. (2018). Developmental Origins of Chronic Physical Aggression : A Bio-Psycho-Social Model for the Next Generation of Preventive Interventions. Annual Review of Psychology, 69(1), 383-407. https://doi.org/10.1146/annurev-psych-010416-044030 
Turecki, G., \& Brent, D. A. (2016). Suicide and suicidal behaviour. Lancet (London, England), 387(10024), 1227-1239. https://doi.org/10.1016/S0140-6736(15)00234-2

Turecki, G., Ernst, C., Jollant, F., Labonté, B., \& Mechawar, N. (2012). The neurodevelopmental origins of suicidal behavior. Trends in Neurosciences, 35(1), 14-23. https://doi.org/10.1016/j.tins.2011.11.008

Tuvblad, C., \& Baker, L. A. (2011). Human aggression across the lifespan: Genetic propensities and environmental moderators. Advances in Genetics, 75, 171-214. https://doi.org/10.1016/B978-0-12$380858-5.00007-1$

Vitaro, F., Barker, E. D., Boivin, M., Brendgen, M., \& Tremblay, R. E. (2006). Do Early Difficult Temperament and Harsh Parenting Differentially Predict Reactive and Proactive Aggression? Journal of Abnormal Child Psychology, 34(5), 681-691. https://doi.org/10.1007/s10802-006-9055-6

Waltes, R., Chiocchetti, A. G., \& Freitag, C. M. (2016). The neurobiological basis of human aggression : A review on genetic and epigenetic mechanisms. American Journal of Medical Genetics Part B: Neuropsychiatric Genetics, 171(5), 650-675. https://doi.org/10.1002/ajmg.b.32388

WHO. (2015). WHO | Suicide data. Consulté 24 février 2018, à l'adresse WHO website: http://www.who.int/mental_health/prevention/suicide/suicideprevent/en/

Zai, C. C., de Luca, V., Strauss, J., Tong, R. P., Sakinofsky, I., \& Kennedy, J. L. (2012). Genetic Factors and Suicidal Behavior. In Y. Dwivedi (Éd.), The Neurobiological Basis of Suicide. Consulté à l'adresse http://www.ncbi.nlm.nih.gov/books/NBK107191/ 


\section{Figure legends}

Figure 1. Genetic and environmental influences on the association between impulsive-aggression and suicidality

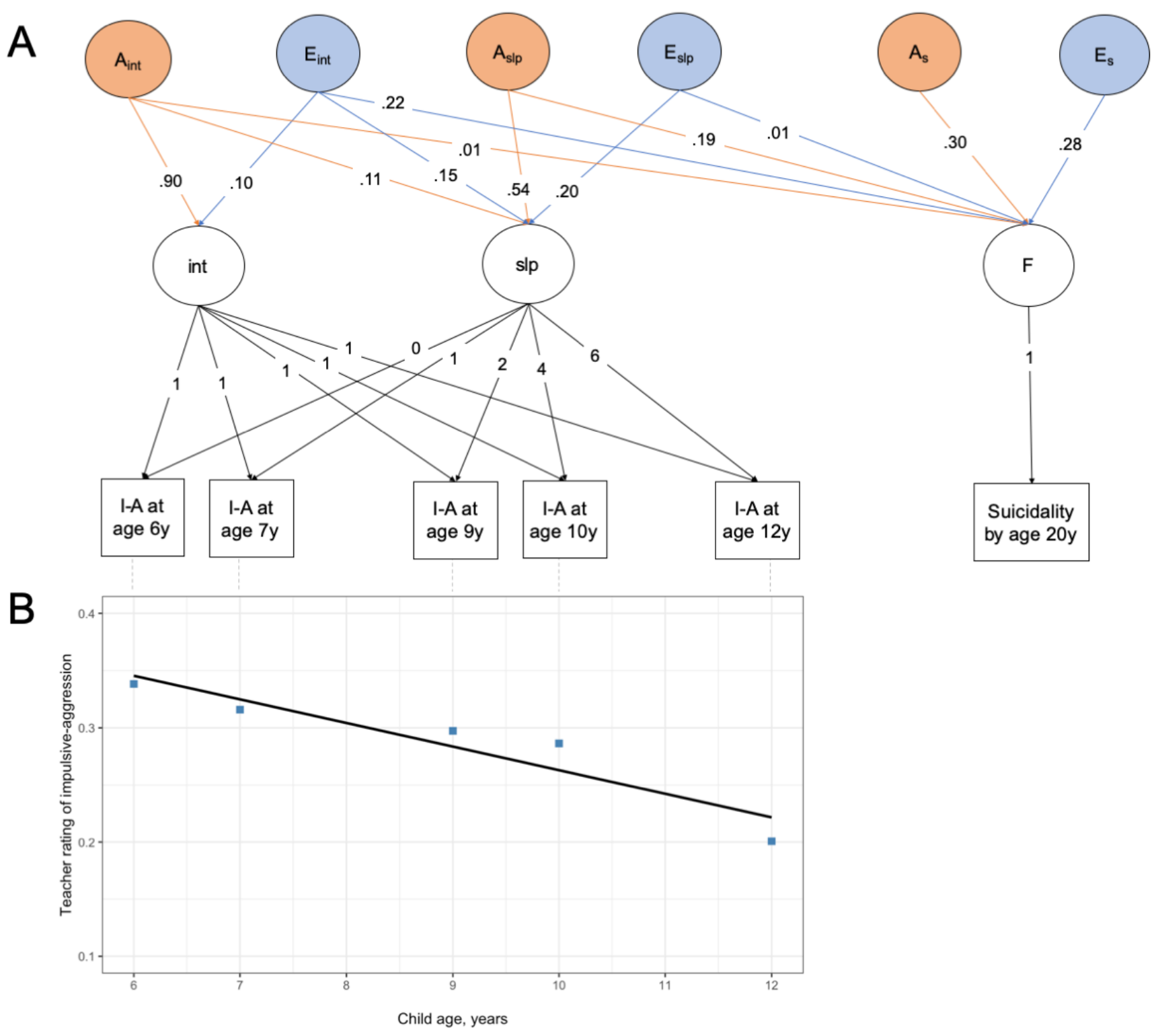

The figure shows the proportion of variance explained by the different genetic (A) and unique environmental (E) influences (part A). Int and slp are, respectively, the intercept and slope parameters of the growth curve model describing the development of impulsive-aggression (I-A) over time. The observed (dots) and estimated (line) impulsive-aggression values are represented in part B (phenotypic model). Fit indices for the final model were as follows (Hu \& Bentler, 1999): Chi-square 192.9 (141 DF); Root Mean Square Error of Approximation 0.04, (good fit if $<0.05$ ); Comparative Fit Indices 0.913 (good fit if $>0.90$ ); Tukey-Lewis Fit Indices 0.918 (good fit if $>0.90$ ). Fit indices for the phenotypic model were as follows: Chi-square 59.9 (10 DF); Root Mean Square Error of Approximation 0.08, (good fit if $<0.05$ ); Comparative Fit Indices 0.925 (good fit if $>0.90)$; Tukey-Lewis Fit Indices 0.925 (good fit if $>0.90)$. 
Table 1. Characteristics of the study sample $(\mathrm{N}=862)$

\begin{tabular}{lc}
\hline & $\boldsymbol{n}(\mathbf{\%})$ \\
\hline Male sex & $355(41.2)$ \\
Monozygotic twins & $318(36.9)$ \\
Low family income & $63(7.3)$ \\
Low maternal education & $113(13.1)$ \\
Teenage mother at child birth & $7(0.8)$ \\
Single mother family & $25(2.9)$ \\
Low birthweight $(<2500 \mathrm{~g})$ & $343(39.79)$ \\
Maternal smoking in pregnancy & $163(18.87)$ \\
Maternal depression & \\
Paternal depression & $17.63(5.31)$ \\
Family functioning & $17.03(4.48)$ \\
Hostile-reactive parenting & $8.86(4.97)$ \\
Physical aggression at age $11 / 2^{\mathrm{a}}$ & $1.40(1.50)$ \\
Hyperactivity at age $11 / 2^{\mathrm{a}}$ & $0.47(0.42)$ \\
Opposition at $11 / 2^{\mathrm{a}}$ & $0.77(0.50)$ \\
Anxiety at age $11 / 2^{\mathrm{a}}$ & $0.79(0.60)$ \\
Impulsive-aggression at age $6^{\mathrm{a}}$ & $0.28(0.39)$ \\
Impulsive-aggression at age $7^{\mathrm{a}}$ & $0.33(0.49)$ \\
Impulsive-aggression at age $9^{\mathrm{a}}$ & $0.30(0.46)$ \\
Impulsive-aggression at age $10^{\mathrm{a}}$ & $0.30(0.49)$ \\
Impulsive-aggression at age $12^{\mathrm{a}}$ & $0.29(0.47)$ \\
\hline
\end{tabular}

Variables are measured when the child was 6 months old, if not otherwise specified. Missing data rate for each measure of impulsive aggression from 6 to 12 year of age was 35, 30, 33, 30, and 40\% respectively.

${ }^{\text {a }}$ Mean (SD) 
Table 2. Rate of suicidality and serious suicidal ideation with and without suicide attempt in the study sample

\begin{tabular}{|c|c|c|c|c|c|}
\hline & \multirow[b]{2}{*}{$\begin{array}{l}\text { All twins } \\
(\mathrm{N}=862)\end{array}$} & \multicolumn{2}{|l|}{ By zygosity } & \multicolumn{2}{|l|}{ By sex } \\
\hline & & $\begin{array}{l}\text { Monozygotic } \\
(\mathrm{N}=335)\end{array}$ & $\begin{array}{l}\text { Dizygotic } \\
(\mathrm{N}=527)\end{array}$ & $\begin{array}{l}\text { Boys } \\
(\mathrm{N}=355)\end{array}$ & $\begin{array}{l}\text { Girls } \\
(\mathrm{N}=507)\end{array}$ \\
\hline $\begin{array}{l}\text { Serious suicidal ideation } \\
\text { but no attempt, n (\%) }\end{array}$ & $59(6.8)$ & $17(5.1)$ & $42(7.9)$ & $30(7.7)$ & $29(6.1)$ \\
\hline $\begin{array}{l}\text { Serious suicidal ideation } \\
\text { and attempt, } \mathrm{n}(\%)\end{array}$ & $20(2.3)$ & $6(1.8)$ & $14(2.6)$ & $7(0.9)$ & $13(2.8)$ \\
\hline $\begin{array}{l}\text { Suicidality, i.e., serious } \\
\text { suicidal ideation and/or } \\
\text { attempt, n }(\%)\end{array}$ & $79(9.1)$ & $23(6.9)$ & $56(10.2)$ & $37(9.4)$ & $42(8.9)$ \\
\hline
\end{tabular}


Table 3. Phenotypic associations

\begin{tabular}{|c|c|c|c|c|c|c|}
\hline & \multirow{2}{*}{$\begin{array}{c}\text { ORs (CIs) } \\
\text { impulsive- } \\
\text { aggression on } \\
\text { suicidality }\end{array}$} & \multicolumn{5}{|c|}{ Correlations between impulsive-aggression and suicidality } \\
\hline & & $\begin{array}{l}\text { Suicidality } \\
\text { by } 20 \text { years }\end{array}$ & 6 years & 7 years & 9 years & 10 years \\
\hline \multicolumn{7}{|l|}{ All twins $(\mathrm{N}=864)$} \\
\hline Suicidal ideation/attempt 20y & & 1 & & & & \\
\hline Impulsive-aggression age $6 y$ & $1.40(0.82-2.39)$ & 0.11 & 1.00 & & & \\
\hline Impulsive-aggression age $7 \mathrm{y}$ & $1.29(0.76-2.18)$ & 0.06 & 0.39 & 1.00 & & \\
\hline Impulsive-aggression age $9 \mathrm{y}$ & $1.47(0.89-2.44)$ & 0.11 & 0.30 & 0.47 & 1.00 & \\
\hline Impulsive-aggression age $10 \mathrm{y}$ & $1.27(0.73-2.18)$ & 0.07 & 0.26 & 0.43 & 0.60 & 1.00 \\
\hline Impulsive-aggression age $12 \mathrm{y}$ & $2.33(1.29-4.19)$ & 0.26 & 0.24 & 0.37 & 0.54 & 0.51 \\
\hline \multicolumn{7}{|l|}{ Monozygotic twins $(\mathbf{N}=\mathbf{3 3 5})$} \\
\hline Suicidal ideation/attempt 20y & & 1.00 & & & & \\
\hline Impulsive-aggression age 6y & $1.34(0.50-3.63)$ & 0.09 & 1.00 & & & \\
\hline Impulsive-aggression age $7 y$ & $1.42(0.55-3.65)$ & 0.07 & 0.44 & 1.00 & & \\
\hline Impulsive-aggression age 9y & $1.76(0.80-3.85)$ & 0.23 & 0.33 & 0.50 & 1.00 & \\
\hline Impulsive-aggression age $10 \mathrm{y}$ & $1.35(0.56-3.24)$ & 0.13 & 0.35 & 0.42 & 0.63 & 1.00 \\
\hline Impulsive-aggression age $12 \mathrm{y}$ & $3.31(1.27-8.64)$ & 0.53 & 0.23 & 0.32 & 0.65 & 0.52 \\
\hline \multicolumn{7}{|l|}{ Dizygotic twins $(\mathrm{N}=\mathbf{5 2 7})$} \\
\hline Suicidal ideation/attempt 20y & & 1.00 & & & & \\
\hline Impulsive-aggression age $6 y$ & $1.37(0.72-2.63)$ & 0.11 & 1.00 & & & \\
\hline Impulsive-aggression age $7 \mathrm{y}$ & $1.24(0.66-2.32)$ & 0.05 & 0.37 & 1.00 & & \\
\hline Impulsive-aggression age 9y & $1.36(0.68-2.70)$ & 0.05 & 0.29 & 0.45 & 1.00 & \\
\hline Impulsive-aggression age $10 \mathrm{y}$ & $1.25(0.63-2.46)$ & 0.04 & 0.20 & 0.45 & 0.58 & 1.00 \\
\hline Impulsive-aggression age $12 \mathrm{y}$ & $1.98(0.92-4.23)$ & 0.13 & 0.28 & 0.42 & 0.45 & 0.50 \\
\hline
\end{tabular}

The table reports: (1) Odds Ratios and 95\% confidence intervals for the increase in suicidality risk for onepoint increase in impulsive-aggression score; (2) the correlation matrix between impulsive-aggression and suicidality measures; biserial correlation was used to estimate the correlation between suicidality and impulsive-aggression. The biserial correlations between the intercept and growth factor and suicidality are, respectively: 0.12 and 0.19 for the entire sample, 0.16 and 0.35 for monozygotic twins, 0.19 and 0.12 for dizygotic twins. 
Table 4. Standardized genetic and environmental variance components (Cholesky decomposition)

\begin{tabular}{|c|c|c|c|c|}
\hline & \multicolumn{3}{|c|}{ Variance components } & \multirow{2}{*}{$\begin{array}{c}\text { Total genetic and } \\
\text { environmental } \\
\text { variance }\end{array}$} \\
\hline & $\begin{array}{c}\text { Impulsive-aggression } \\
\text { intercept }\end{array}$ & $\begin{array}{c}\text { Impulsive-aggression } \\
\text { slope }\end{array}$ & Suicidality & \\
\hline \multicolumn{5}{|l|}{ Additive genetic } \\
\hline Impulsive-aggression intercept & $0.90(0.74-1.00)$ & - & - & $0.90(0.74-1.00)$ \\
\hline Impulsive-aggression slope & $0.11(0.00-0.39)$ & $0.54(0.25-0.93)$ & - & $0.65(0.23-0.99)$ \\
\hline Suicidality & $0.01(0.00-0.04)$ & $0.19(0.00-0.68)$ & $0.30(0.00-0.74)$ & $0.50(0.17-0.79)$ \\
\hline \multicolumn{5}{|l|}{ Unique environmental } \\
\hline Impulsive-aggression intercept & $0.10(0.00-0.26)$ & - & - & $0.10(0.00-0.26)$ \\
\hline Impulsive-aggression slope & $0.15(0.00-0.63)$ & $0.20(0.01-0.67)$ & - & $0.35(0.01-0.77)$ \\
\hline Suicidality & $0.22(0.00-0.73)$ & $0.01(0.00-0.08)$ & $0.28(0.00-0.93)$ & $0.50(0.21-0.83)$ \\
\hline
\end{tabular}

For each row, the total variance is the sum of each variance components. For example, the total genetic variance of impulsive-aggression slope (0.65) is equal to the shared variance between impulsive-aggression intercept and slope (0.11), plus the residual variance of impulsive-aggression slope (0.54). For each measure (ie, impulsive-aggression intercept, slope, and suicidality factors), the genetic and environmental variance components sum up to 1 ; eg, for suicidality the sum of genetic $(0.50)$ and unique environmental $(0.50)$ variance components is 1 . 


\section{Key points}

- Impulsive-aggression is a main behavioral risk factor for suicide, but it is unknown to what extent genetic and environmental factors contribute to this association

- Genetic and environmental factors underlying adolescent suicidality significantly overlap with genetic and environmental factors underlying childhood impulsive-aggression.

- The genetic and environmental factors underlying baseline level of impulsive-aggression (6 years) and those associated with changes in impulsive-aggression during childhood (6 to 12 years) differently contributed to suicidality

- Future studies should identify putative genetic and environmental factors accounting for the association between impulsive-aggression and suicidality using a developmental perspective 